\title{
AVALIAÇÃO DE OCORRÊNCIA DE MANIFESTAÇÕES PATOLÓGICAS EM SISTEMAS PREDIAIS HIDROSSANITÁRIOS NOS PRIMEIROS ANOS DE USO E OPERAÇÃO
}

\author{
Evaluation of the occurrence of pathological manifestations in plumbing \\ systems in the first years of use and operation \\ MORAIS, Lucas Salomão Rael${ }^{1}$; PAULA, Heber Martins²; REIS, Ricardo Prado Abreu³
}

Recebido em 15 de julho de 2021, aprovado em 06 de setembro de 2021, publicado em 18 de novembro de 2021

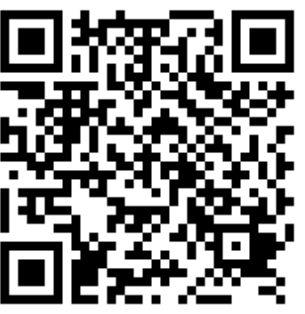

Palavras-chave:

Sistemas prediais hidrossanitários,

Patologias de construção,

Manutenção predial.

Keywords:

Plumbing systems,

Building Pathologies,

Building maintenance.
RESUMO: Considerando que as ações de avaliação de desempenho de edificações e de manutenção predial vêm ganhando ênfase nos últimos anos, a identificação de patologias nos sistemas prediais e a sua detecção precoce estão sendo tratadas mais a sério. Destaca-se o grande número de registros de patologias nos sistemas prediais hidrossanitários (SPHS), devido as características de heterogeneidade de seus elementos e o elevado grau de interação com os usuários. Este artigo tem o objetivo de avaliar a ocorrência de manifestações patológicas em edifícios públicos nos seus primeiros anos de uso e operação através da avaliação de relatórios de ordens de serviço de manutenção predial da Universidade Federal de Goiás durante o período de 2012 a 2019. A partir dessas informações, foi avaliada a participação das edificações com pouca idade na manutenção predial da instituição e identificados quais foram os tipos de manifestações patológicas relatadas nesses edifícios. Observou-se participação significativa de edifícios com menos de 5 anos nas requisições de manutenção dos SPHS. A ocorrência de manifestações patológicas foi relacionada ao uso de materiais de baixa qualidade e deficiências nas etapas de projeto, execução e fiscalização da obra.

ABSTRACT: Considering that building performance assessment and building maintenance actions have been gaining emphasis in recent years, the identification of pathologies in building systems and their early detection are being treated more seriously. The large number of records of pathologies in plumbing systems stands out, due the heterogeneous characteristics of their elements and the high degree of interaction with users. This paper aims to assess the occurrence of pathological manifestations in public buildings in their first years of use and operation through the evaluation of building maintenance order reports from the Federal University of Goiás during 2012 to 2019. Based on this information, it was sought to assess the participation of young buildings in the institution's building maintenance and identify the types of pathological manifestations reported in these buildings. There was a significant participation of buildings with less than 5 years in maintenance requests from the institution's plumbing facilities. The occurrence of pathological manifestations was related to the use of low-quality materials and deficiencies in the design, execution and inspection stages of the work.

CONTATO DOS AUTORES:

${ }^{1}$ MORAIS, LUCAS SALOMÃo RAEL: Mestrando em Engenharia Civil do Programa de Pós-graduação em Engenharia Civil da Universidade Federal Catalão, lucas.salomao@ufg.br

2 PAULA, HEBER MARTINS: Eng. Civil, Doutor, Professor do Programa de Pós-graduação em Engenharia Civil da Universidade Federal Catalão, heberdepaula@ufcat.edu.br

${ }^{3}$ REIS, RICARDO PRADO ABREU: Eng. Civil, Doutor, Professor da Escola de Engenharia Civil e Ambiental da Universidade Federal de Goiás, ricardo_reis@ufg.br 


\section{INTRODUÇÃO}

A ocorrência de manifestações patológicas tem sido detectada de forma cada vez mais precoce devido ao avanço de novas tecnologias construtivas, ao uso de materiais não convencionais e ao aumento do número de sistemas prediais em uma edificação (CRUZ, 2013). Considerando o impacto negativo dessas anomalias na satisfação do usuário, é importante a melhoria constante do desempenho das edificações. BOSCHETTI (2010) aponta que 80\% das falhas dos sistemas prediais registradas nos cinco primeiros anos pós-obra são incidentes no primeiro ano após a entrega do empreendimento e que $50 \%$ dos recursos financeiros destinados a execução de atividades de manutenção durante a garantia do empreendimento são consumidos nos dois primeiros anos de uso e operação dos edifícios.

A perda de eficiência das instalações e o aparecimento de falhas pós-obra podem estar relacionados a diversos fatores associados à concepção e projeto, execução e operação. As deficiências de projeto podem ser resultados de erros de concepção, falhas na especificação de materiais e componentes, dimensionamento incorreto, falta de detalhamento e até mesmo incompatibilidade entre os demais projetos (SANTOS et. al, 2020). Quando a origem é relacionada a etapa de execução da obra, influenciam fatores como o emprego de materiais inadequados e de baixa qualidade, mão de obra desqualificada e desconformidade entre a velocidade de execução e a atuação da fiscalização (BOSCHETTI, 2010). De forma menos significativa, os usuários contribuem nesse processo, principalmente pelo uso inadequado dos equipamentos (TEIXEIRA, 2011).

Os sistemas prediais hidrossanitários (SPHS) destacam-se pelo elevado registro de manifestações patológicas nos primeiros anos de uso e operação de uma edificação (CRUZ, 2013; TEIXEIRA, 2011) que é potencializada por características peculiares desse sistema como a heterogeneidade de seus componentes e devido ao grande número de solicitações em função das necessidades dos usuários.

PRADO (2017) pontua que essas adversidades nos SPHS são caracterizadas por serem eventos em ocorrência e de tendência evolutiva, ou seja, podem se agravar ao longo do tempo e causar enormes prejuízos financeiros caso não sejam sanados.

Considerando o cenário de poucas pesquisas relacionadas ao período de uso e ocupação das edificações, principalmente nos primeiros anos após a entrega da obra, torna-se necessário aprofundar no conhecimento das falhas e suas origens, a fim de evitá-las em futuros empreendimentos.

Portanto, este artigo tem como objetivo avaliar a ocorrência de manifestações patológicas nos sistemas prediais hidrossanitários de edifícios públicos nos seus primeiros anos de uso e operação através da avaliação de relatórios de ordens de serviço de manutenção predial da Universidade Federal de Goiás durante o período de 2012 a 2019. Busca-se observar os problemas mais frequentes durante os primeiros anos de ocupação dos edifícios, suas causas e verificar o desempenho dos SPHS junto a outras edificações já existentes e com idades mais avançadas.

\section{MATERIAL E MÉTODOS}

Para a avaliação dos dados, foram solicitados os relatórios de ordens de serviço de manutenção predial para a instituição, sendo objeto deste estudo as requisições dos anos de 2012 a 2019, referentes aos edifícios da Universidade Federal de Goiás, localizados na cidade de Goiânia (GO). Foi realizado um levantamento de identificação das edificações, buscando 
obter informações de área construída, tipologia de uso e da data de finalização ou inauguração da construção (considerou-se como critério a data mais recente).

Obtidos os relatórios de manutenção da instituição, iniciou-se a etapa de classificação das requisições de serviço. A partir de categorias existentes nos relatórios, foram separadas as requisições referentes aos SPHS. Dentro desse universo, foi realizada a leitura de cada requisição para classificação em função do tipo de sistema: água fria, esgoto sanitário ou águas pluviais. Como critério de classificação e avaliação das requisições em relação ao sistema predial correspondente, foi considerado o tipo de fluido que é conduzido pelo componente, peça sanitária ou louça.

As requisições foram então agrupadas em função do edifício de localização do serviço. Para possibilitar o estudo comparativo de edificações com áreas construídas diferentes, foi adotado o parâmetro de número de requisições por $100 \mathrm{~m}^{2}$ (adaptado de MORAIS e LORDSLEEM (2018)). A partir dessas informações, buscou-se avaliar a participação das edificações com pouca idade na manutenção predial da instituição dentro do período.

Em função do grande número de edificações identificadas, foram selecionadas as 20 edificações com maior número de requisições por $100 \mathrm{~m}^{2}$ de área construída. Dentre elas, foram escolhidas duas edificações que tiveram data de entrega da obra durante o intervalo de tempo avaliado. Para essas edificações, observou-se o quantitativo de ordens de serviço recebidas durante os primeiros anos de uso e operação. Esses resultados foram confrontados com edificações com tipologias de uso semelhantes, mas com idades mais avançadas, a fim de encontrar similaridades ou discrepância de resultados.

Nos edifícios novos, buscou-se ainda identificar quais foram os tipos de manifestações patológicas relatadas nos primeiros anos, para verificação de quais delas foram as mais frequentes e quais as possíveis causas de ocorrência.

\section{RESULTADOS E DISCUSSÃO}

Durante a catalogação das edificações existentes, para o ano de 2019 foram verificados 175 edifícios no órgão objeto de estudo. Através do Quadro 1, é apresentada a evolução de área construída da instituição durante o levantamento, onde observa-se um crescimento de requisições na maioria do período e a incorporação de novos edifícios à estrutura física da universidade ao longo dos anos.

Quadro 1 - Evolução anual de área construída acumulada e requisições de manutenção predial em números absolutos e por $100 \mathrm{~m}^{2}$ de área construída

\begin{tabular}{|c|c|c|c|}
\hline Ano & Área Construída $\left(\mathbf{m}^{\mathbf{2}} \mathbf{)}\right.$ & Total de Requisições & $\begin{array}{c}\text { No de requisições a } \\
\text { cada } \mathbf{1 0 0} \mathbf{~} \mathbf{2}^{\mathbf{2}}\end{array}$ \\
\hline 2012 & $220.499,15$ & 9.464 & 4,292 \\
\hline 2013 & $230.553,04$ & 11.918 & 5,169 \\
\hline 2014 & $237.185,91$ & 12.029 & 5,072 \\
\hline 2015 & $242.233,80$ & 12.659 & 5,226 \\
\hline 2016 & $291.332,65$ & 13.048 & 4,479 \\
\hline 2017 & $298.304,03$ & 13.635 & 4,571 \\
\hline 2018 & $300.984,96$ & 13.044 & 4,334 \\
\hline 2019 & $304.034,23$ & 11.928 & 3,923 \\
\hline
\end{tabular}

Fonte: Autoria Própria. 
O Quadro 2 apresenta o percentual de área construída e de número de requisições que as 20 edificações selecionadas representam em relação ao total levantado. Observa-se que o percentual representativo do número de requisições dessas edificações corresponde a valores bem superiores que o percentual de área construída, sendo que em quase todo o período o percentual de número de requisições representa o dobro da área construída proporcional.

Quadro 2 - Percentual de número de requisições e área construída em relação aos dados totais das 20 edificações selecionadas

\begin{tabular}{|l|c|c|c|c|c|c|c|c|}
\hline \multicolumn{1}{|c|}{ Ano } & $\mathbf{2 0 1 9}$ & $\mathbf{2 0 1 8}$ & $\mathbf{2 0 1 7}$ & $\mathbf{2 0 1 6}$ & $\mathbf{2 0 1 5}$ & $\mathbf{2 0 1 4}$ & $\mathbf{2 0 1 3}$ & $\mathbf{2 0 1 2}$ \\
\hline Percentual do no de requisições & $31,92 \%$ & $37,18 \%$ & $39,09 \%$ & $37,93 \%$ & $36,41 \%$ & $36,64 \%$ & $34,63 \%$ & $48,04 \%$ \\
\hline $\begin{array}{l}\text { Percentual da área construída em } \\
\text { relação ao total }\end{array}$ & $17,48 \%$ & $18,69 \%$ & $19,19 \%$ & $16,77 \%$ & $18,39 \%$ & $19,30 \%$ & $21,53 \%$ & $22,85 \%$ \\
\hline
\end{tabular}

Fonte: Autoria Própria.

A Figura 1 apresenta a faixa de idade das 20 edificações com maiores números de requisições por $100 \mathrm{~m}^{2}$. Durante o período de 2013 a 2017, as edificações com idades de 0 a 5 anos representaram mais de $35 \%$ de todas as edificações, com destaque para o ano de 2013, quando esses edifícios novos representaram 45\% do total. A partir do ano de 2018 houve um aumento de participação das edificações acima de 6 anos de idade, que pode ser explicado pela redução de novas construções a partir desse ano e o avanço da idade das edificações existentes.

\section{Figura 1 - Participação das faixas de idades das edificações avaliadas nas requisições de manutenção}

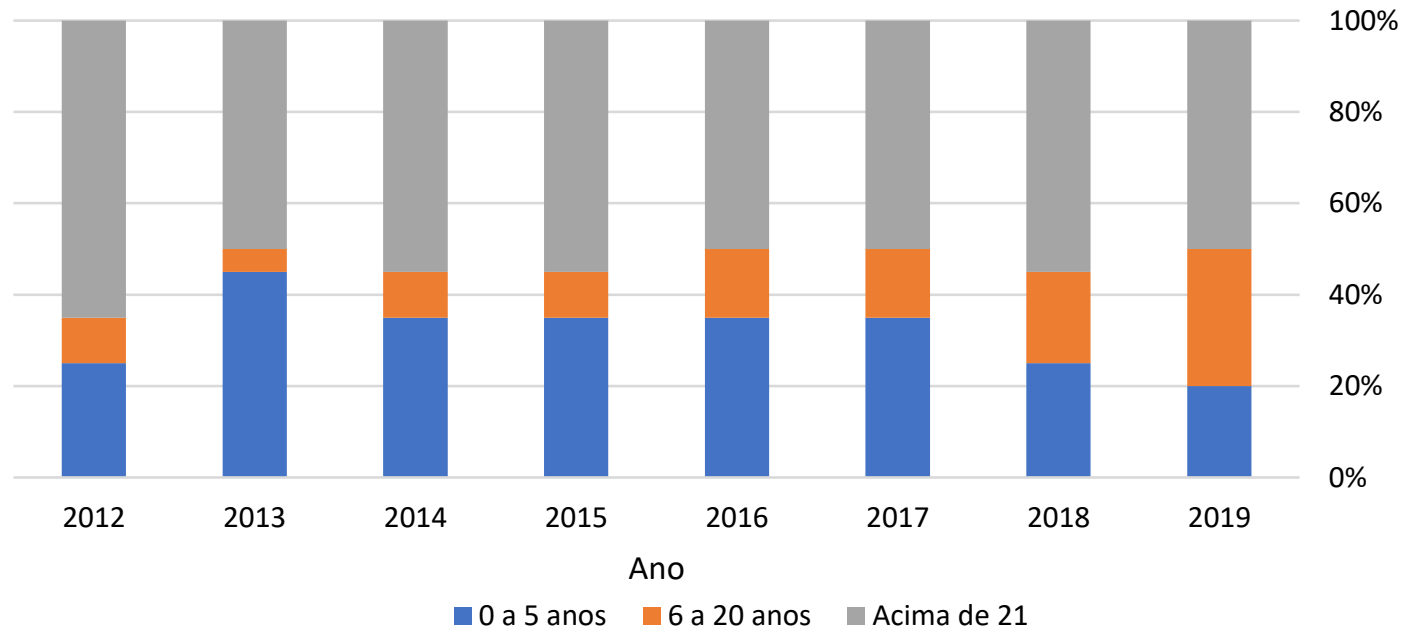

Fonte: Autoria Própria.

As edificações escolhidas para a avaliação das requisições de manutenção predial nos primeiros anos de uso e operação foram o Centro de Aulas $D$ e a Faculdade de Farmácia, que representam uma amostra de edificações na faixa de cinco e sete anos de idade no ano de 2019.

\subsection{Centro de Aulas D}

O Centro de Aulas $D$ é destinado ao uso como salas de aula multidisciplinares, tem área construída de $15.459,42 \mathrm{~m}^{2}$ e teve data de conclusão da obra em meados do ano de 2012 . A 
data de início das atividades de uso e operação é desconhecida, mas presume-se a partir dos dados observados que tenha ocorrido a partir do ano de 2013. A Figura 2 apresenta o número de requisições por $100 \mathrm{~m}^{2}$ a partir de 2012, sendo que nesse ano foram observadas 27 solicitações, seguido de crescimento pelos dois anos seguintes e variações a partir do 4ำ ano.

Figura 2 - Evolução temporal do número de requisições $/ 100 \mathrm{~m}^{2}$ do Centro de Aulas $\mathrm{D}$

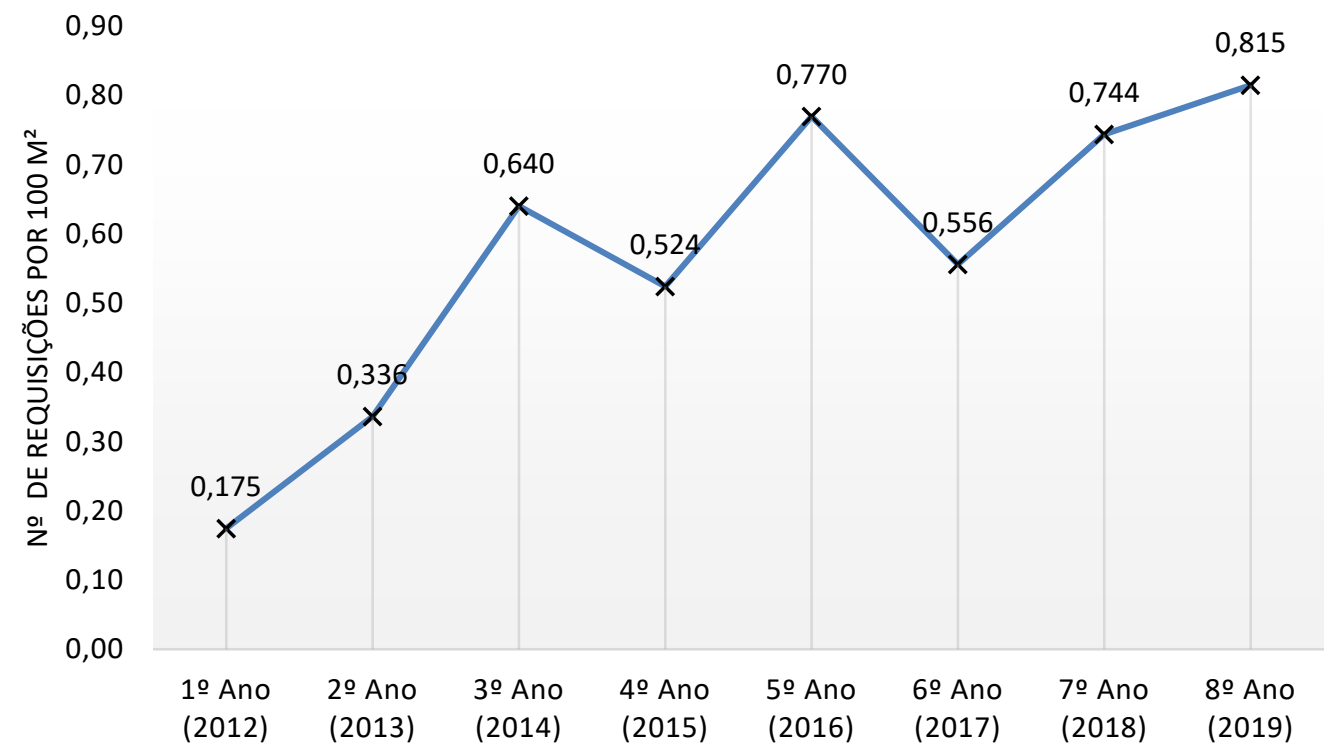

Fonte: Autoria Própria.

Comparando este edifício com o Centro de Aulas Mangaba, edificação com idade mais avançada mas com mesma tipologia de uso, observa-se através do Quadro 3 que a média de requisições do Centro de Aulas $D$ foi menor que para o edifício mais antigo.

\section{Quadro 3 - Comparação das médias de número de requisições $/ 100 \mathrm{~m}^{2}$ entre centros de aulas com datas de construção diferentes.}

\begin{tabular}{|l|c|c|c|}
\hline \multicolumn{1}{|c|}{ Edifício } & $\begin{array}{c}\text { Ano Término } \\
\text { de Construção }\end{array}$ & $\begin{array}{c}\text { Média de } \mathbf{n} \mathbf{0} \text { de } \\
\text { Requisições } / \mathbf{1 0 0} \mathbf{~ m}^{\mathbf{2}}\end{array}$ & Uso \\
\hline Centro de Aulas D & 2012 & 0,570 & Salas de Aulas \\
\hline Centro de Aulas Mangaba & 2004 & 1,232 & Salas de Aulas \\
\hline
\end{tabular}

Fonte: Autoria Própria.

Os Quadros 4, 5 e 6 discriminam os tipos de solicitações recebidas nos cinco primeiros anos de uso e operação do Centro de Aulas $D$, após o término da construção e em função do tipo de sistema. Solicitações relacionadas ao sistema de esgoto sanitário foram a maioria em todos os períodos, ressaltando a ocorrência de entupimentos de ralos e de bacias sanitárias. 0 50 ano se destaca pela incidência de todos os tipos de manifestações patológicas registradas e pelo elevado registro de entupimentos de mictórios. Em relação ao sistema de água fria, a falta de água na edificação foi bastante relatada durante o 20 e 50 ano. Cabe destacar as demandas relacionadas a alagamentos nos pavimentos de subsolo e no poço de elevador, que é um problema reincidente durante os episódios de fortes chuvas, o que pode ser causado devido à problemas de concepção e subdimensionamento do sistema de drenagem de águas pluviais. Requisições referentes a instalação e manutenção em bebedouros se referem a intervenções nos componentes que fazem a interface entre o SPHS e parte do equipamento (engate e sifão). 
Quadro 4-Manifestações patológicas e demandas de manutenção relatadas nos primeiros 5 anos pós-obra do “Centro de Aulas D” do sistema de água fria.

\begin{tabular}{|l|c|c|c|c|c|}
\hline \multicolumn{1}{|c|}{ Água Fria } & $\begin{array}{c}\mathbf{1 0} \text { Ano } \\
\mathbf{( 2 0 1 2 )}\end{array}$ & $\begin{array}{c}\mathbf{2 0} \text { Ano } \\
\text { (2013) }\end{array}$ & $\begin{array}{c}\text { 30 Ano } \\
\text { (2014) }\end{array}$ & $\begin{array}{c}\text { 40 Ano } \\
\text { (2015) }\end{array}$ & $\begin{array}{c}\text { 50 Ano } \\
\text { (2016) }\end{array}$ \\
\hline $\begin{array}{l}\text { Instalação e manutenção em } \\
\text { bebedouros }\end{array}$ & 4 & 3 & 2 & 2 & 3 \\
\hline Vazamentos e defeitos em torneiras & 2 & - & - & 2 & 5 \\
\hline $\begin{array}{l}\text { Vazamentos e defeitos em válvulas de } \\
\text { descarga }\end{array}$ & 2 & 1 & 15 & 8 & 13 \\
\hline Vazamentos e falhas em reservatórios & 2 & - & 7 & 6 & 4 \\
\hline Falta de água & - & 10 & 4 & 1 & 9 \\
\hline Vazamentos em tubulações & - & 2 & 6 & 3 & 5 \\
\hline Instalação de equipamentos & - & 1 & - & 0 & 0 \\
\hline Vazamentos e defeitos em engates & - & - & 1 & 0 & 0 \\
\hline Pressão inadequada & - & - & - & - & 1 \\
\hline \multicolumn{1}{|c|}{ Total } & $\mathbf{1 0}$ & $\mathbf{1 7}$ & $\mathbf{3 5}$ & $\mathbf{2 2}$ & $\mathbf{4 0}$ \\
\hline & $\mathbf{2 9 , 4 1 \%}$ & $\mathbf{3 2 , 0 8 \%}$ & $\mathbf{3 3 , 0 2 \%}$ & $\mathbf{2 8 , 2 1 \%}$ & $\mathbf{3 6 , 0 4 \%}$ \\
\hline
\end{tabular}

Fonte: Autoria Própria

Quadro 5 - Manifestações patológicas e demandas de manutenção relatadas nos primeiros 5 anos pós-obra do "Centro de Aulas D" do sistema de esgoto sanitário.

\begin{tabular}{|l|c|c|c|c|c|}
\hline \multicolumn{1}{|c|}{ Esgoto Sanitário } & $\begin{array}{c}\mathbf{1 0} \text { Ano } \\
\text { (2012) }\end{array}$ & $\begin{array}{c}\text { 20 Ano } \\
\text { (2013) }\end{array}$ & $\begin{array}{c}\text { 30 Ano } \\
\text { (2014) }\end{array}$ & $\begin{array}{c}\text { 4o Ano } \\
\text { (2015) }\end{array}$ & $\begin{array}{c}\text { 5o Ano } \\
\text { (2016) }\end{array}$ \\
\hline $\begin{array}{l}\text { Instalação e manutenção em } \\
\text { bebedouros }\end{array}$ & 8 & 10 & 10 & 2 & 2 \\
\hline Vazamentos e defeitos em sifões & - & 4 & 4 & 4 & 6 \\
\hline Entupimentos em sifões & 2 & - & 4 & 1 & 3 \\
\hline Entupimentos em bacias sanitárias & 3 & 12 & 20 & 20 & 17 \\
\hline Entupimentos em ralos & 5 & 4 & 15 & 11 & 6 \\
\hline Descolamento de bacia sanitária & - & 2 & 0 & 0 & 3 \\
\hline Entupimentos em mictórios & - & 1 & 1 & 5 & 15 \\
\hline Tampa de bacia sanitária danificada & 1 & - & 6 & 0 & 6 \\
\hline Vazamentos em tubulações & 2 & 1 & 1 & 1 & 3 \\
\hline \multicolumn{1}{|c|}{ Total } & $\mathbf{2 1}$ & $\mathbf{3 4}$ & $\mathbf{6 1}$ & $\mathbf{4 4}$ & $\mathbf{6 1}$ \\
\hline & $\mathbf{6 1 , 7 6 \%}$ & $\mathbf{6 4 , 1 5 \%}$ & $\mathbf{5 7 , 5 5 \%}$ & $\mathbf{5 6 , 4 1 \%}$ & $\mathbf{5 4 , 9 5 \%}$ \\
\hline
\end{tabular}

Fonte: Autoria Própria

Quadro 6 - Manifestações patológicas e demandas de manutenção relatadas nos primeiros 5 anos pós-obra do "Centro de Aulas D" do sistema de drenagem de águas pluviais.

\begin{tabular}{|l|c|c|c|c|c|}
\hline \multicolumn{1}{|c|}{ Águas Pluviais } & $\begin{array}{c}\text { 10 Ano } \\
\text { (2012) }\end{array}$ & $\begin{array}{c}\text { 29 Ano } \\
\text { (2013) }\end{array}$ & $\begin{array}{c}\text { 39 Ano } \\
\text { (2014) }\end{array}$ & $\begin{array}{c}\text { 40 Ano } \\
\text { (2015) }\end{array}$ & $\begin{array}{c}\text { 50 Ano } \\
\text { (2016) }\end{array}$ \\
\hline Alagamento de poço de elevador & - & 2 & 8 & 7 & 4 \\
\hline Alagamento de pavimento subsolo & 3 & - & 1 & 2 & - \\
\hline Vazamentos e entupimentos em calhas & - & - & 1 & 3 & 6 \\
\hline Total & $\mathbf{3}$ & $\mathbf{2}$ & $\mathbf{1 0}$ & $\mathbf{1 2}$ & 10 \\
\hline Percentual anual & $\mathbf{8 , 8 2 \%}$ & $\mathbf{3 , 7 7 \%}$ & $\mathbf{9 , 4 3 \%}$ & $\mathbf{1 5 , 3 8 \%}$ & $\mathbf{9 , 0 1 \%}$ \\
\hline
\end{tabular}

Fonte: Autoria Própria 


\subsection{Faculdade de Farmácia}

O prédio da Faculdade de Farmácia tem registro de data de abertura à comunidade em abril de 2014, é destinado a atividades de pesquisa e ensino, sendo constituído de laboratórios, auditórios, gabinetes de professores, salas administrativas e algumas salas de aula, com $4.465,00 \mathrm{~m}^{2}$ de área construída e seis pavimentos. Conforme apresentado na Figura 4, essa edificação apresentou mais registros de manutenção predial entre abril e dezembro de 2014 (10 ano de uso) do que durante todo o ano de 2015. Durante os três primeiros anos de vida, os índices de manutenção se mantiveram elevados e após o quarto ano esses valores se reduziram significativamente. Como não foram identificadas grandes intervenções nesse período, pode-se presumir que as atividades de manutenção foram corrigindo algumas falhas originadas na etapa de obras da edificação.

Figura 4 - Evolução temporal do número de requisições $/ 100 m^{2}$ da Faculdade de Farmácia

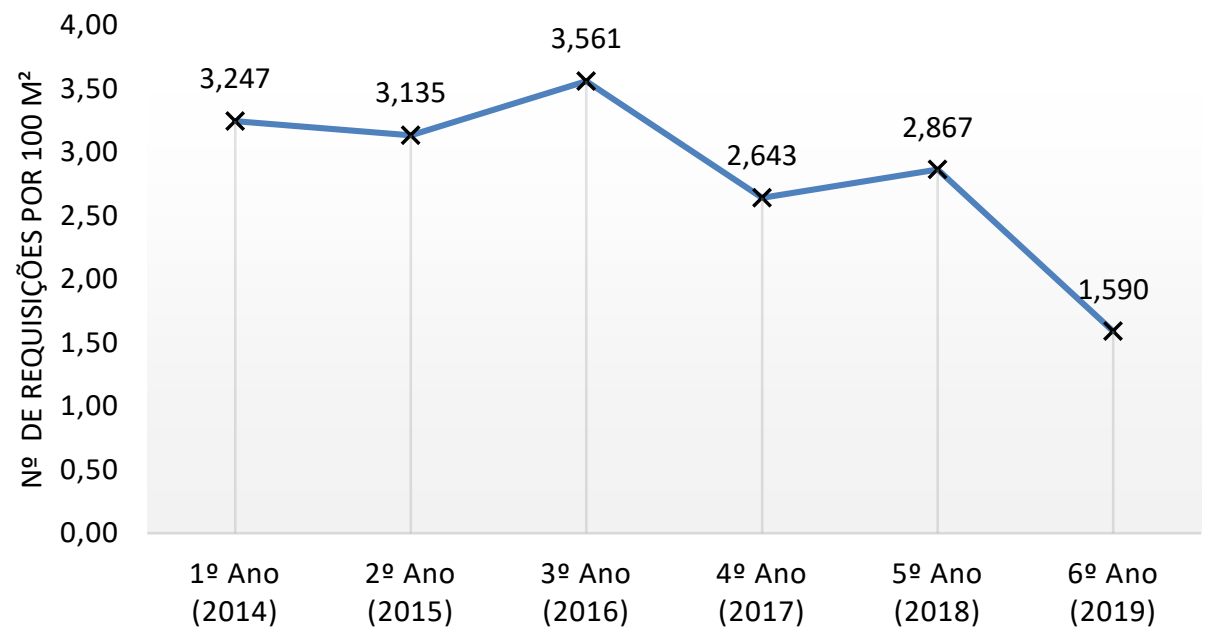

Fonte: Autoria Própria.

Através do Quadro 7, verifica-se que a Faculdade de Farmácia registrou média do número de requisições a cada $100 \mathrm{~m}^{2}$ bem superior ao edifício da Faculdade de Enfermagem, que tem data de construção no ano de 1990 e tem tipologia de uso semelhante (pesquisa e ensino de curso da área da saúde).

Quadro 7 - Comparação das médias de número de requisições $/ 100 \mathrm{~m}^{2}$ entre edifícios de pesquisa e ensino com datas de construção diferentes.

\begin{tabular}{|l|c|c|l|}
\hline \multicolumn{1}{|c|}{ Edifício } & $\begin{array}{c}\text { Ano Término } \\
\text { de Construção }\end{array}$ & $\begin{array}{c}\text { Média de } \mathbf{n} \mathbf{0} \text { de } \\
\text { Requisições } / \mathbf{1 0 0} \mathbf{~ m}^{\mathbf{2}}\end{array}$ & Uso \\
\hline Faculdade de Farmácia & 2014 & 2,841 & Pesquisa/ Sala de Aulas \\
\hline Faculdade de Enfermagem & 1990 & 0,575 & Pesquisa/ Sala de Aulas \\
\hline
\end{tabular}

Fonte: Autoria Própria.

Os Quadros 8, 9 e 10 apresentam as principais manifestações patológicas e demandas de manutenção dos SPHS nos cinco primeiros anos de uso e operação da Faculdade de Farmácia em função do tipo de sistema. Observa-se que os sistemas de água fria e esgoto sanitário concentram a maioria das solicitações durante toda a avaliação. Durante o primeiro ano, destaca-se vazamentos e defeitos em torneiras e reservatórios. Nesse mesmo período, sete entupimentos de sifões e catorze entupimentos em bacias sanitárias foram relatados, número elevado para o primeiro ano de uso de uma edificação. No segundo, terceiro e quinto ano, 
falhas oriundas nos sistemas de águas pluviais refletiram percentuais elevados de relatos. A incidência de entupimentos de componentes foram destaque no sistema de esgoto sanitário para todo o período.

Quadro 8 - Manifestações patológicas e demandas de manutenção relatadas nos primeiros 5 anos pós-obra da Faculdade de Farmácia do sistema de água fria.

\begin{tabular}{|l|c|c|c|c|c|}
\hline \multicolumn{1}{|c|}{ Água Fria } & $\begin{array}{c}\text { 10 Ano } \\
\text { (2014) }\end{array}$ & $\begin{array}{c}\text { 20 Ano } \\
\text { (2015) }\end{array}$ & $\begin{array}{c}\text { 30 Ano } \\
\text { (2016) }\end{array}$ & $\begin{array}{c}\text { 40 Ano } \\
\text { (2017) }\end{array}$ & $\begin{array}{c}\text { 5o Ano } \\
\text { (2018) }\end{array}$ \\
\hline $\begin{array}{l}\text { Instalação e manutenção em } \\
\text { bebedouros }\end{array}$ & 5 & - & 5 & 4 & 2 \\
\hline Vazamentos e defeitos em torneiras & 21 & 25 & 20 & 12 & 11 \\
\hline $\begin{array}{l}\text { Vazamentos e defeitos em válvulas de } \\
\text { descarga }\end{array}$ & 6 & 10 & 11 & 8 & 13 \\
\hline Vazamentos e falhas em reservatórios & 12 & 6 & 8 & 6 & 9 \\
\hline Falta de água & 3 & 2 & 8 & 1 & 0 \\
\hline Pressão insuficiente & 4 & - & 2 & 1 & 0 \\
\hline Vazamentos em tubulações & 4 & 9 & 6 & 9 & 15 \\
\hline Vazamentos e defeitos em registros & 4 & - & 8 & 0 & 1 \\
\hline Instalação de equipamentos & 6 & 10 & 1 & 3 & 0 \\
\hline Vazamentos e defeitos em engates & - & 2 & 4 & 0 & 0 \\
\hline \multicolumn{1}{|r|}{ Potal } & $\mathbf{6 5}$ & $\mathbf{6 4}$ & $\mathbf{7 3}$ & $\mathbf{4 4}$ & $\mathbf{5 1}$ \\
\hline
\end{tabular}

Fonte: Autoria Própria.

Quadro 9 - Manifestações patológicas e demandas de manutenção relatadas nos primeiros 5 anos pós-obra da Faculdade de Farmácia do sistema de esgoto sanitário.

\begin{tabular}{|l|c|c|c|c|c|}
\hline \multicolumn{1}{|c|}{ Esgoto Sanitário } & $\begin{array}{c}\mathbf{1 0} \text { Ano } \\
\mathbf{( 2 0 1 4 )}\end{array}$ & $\begin{array}{c}\mathbf{2 0} \text { Ano } \\
\text { (2015) }\end{array}$ & $\begin{array}{c}\text { 3o Ano } \\
\text { (2016) }\end{array}$ & $\begin{array}{c}\text { 40 Ano } \\
\text { (2017) }\end{array}$ & $\begin{array}{c}\text { 50 Ano } \\
\text { (2018) }\end{array}$ \\
\hline $\begin{array}{l}\text { Instalação e manutenção em } \\
\text { bebedouros }\end{array}$ & 5 & - & 2 & 6 & 2 \\
\hline Vazamentos e defeitos em sifões & 6 & 9 & 8 & 5 & 11 \\
\hline Entupimentos em sifões & 7 & 7 & 2 & 7 & 5 \\
\hline Entupimentos em bacias sanitárias & 14 & 2 & 9 & 16 & 6 \\
\hline Entupimentos em ralos & 6 & 7 & 22 & 12 & 8 \\
\hline Retorno de odor & 7 & 4 & 3 & 0 & 2 \\
\hline Descolamento de pia & 7 & 6 & 10 & 0 & 0 \\
\hline Vazamentos em tubulações & 5 & 1 & 1 & 3 & 7 \\
\hline Instalação de equipamentos & 5 & - & 0 & 1 & 0 \\
\hline Descolamento de bacia sanitária & 2 & - & 0 & 1 & 4 \\
\hline Entupimentos em mictórios & - & - & 2 & 1 & 10 \\
\hline \multicolumn{1}{|c|}{ Percentual anual } & $\mathbf{4 5 , 7 1 \%}$ & $\mathbf{2 9 , 0 3 \%}$ & $\mathbf{3 8 , 7 8 \%}$ & $\mathbf{4 8 , 6 0 \%}$ & $\mathbf{4 4 , 7 2 \%}$ \\
\hline
\end{tabular}

Fonte: Autoria Própria. 


\section{Quadro 10 - Manifestações patológicas e demandas de manutenção relatadas nos primeiros 5 anos pós-obra da Faculdade de Farmácia do sistema de drenagem de águas pluviais.}

\begin{tabular}{|c|c|c|c|c|c|}
\hline Águas Pluviais & $\begin{array}{l}\text { 10 Ano } \\
\text { (2014) }\end{array}$ & $\begin{array}{l}\text { 20 Ano } \\
\text { (2015) }\end{array}$ & $\begin{array}{l}\text { 3o Ano } \\
\text { (2016) }\end{array}$ & $\begin{array}{l}\text { 40 Ano } \\
\text { (2017) }\end{array}$ & $\begin{array}{l}\text { 50 Ano } \\
\text { (2018) }\end{array}$ \\
\hline Vazamentos e entupimentos em calhas & 1 & 4 & 4 & 3 & 4 \\
\hline Ocorrência de goteiras & 10 & 19 & 10 & 6 & 11 \\
\hline Manutenção em telhados & - & 1 & 3 & 2 & 2 \\
\hline Total & 11 & 24 & 17 & 11 & 17 \\
\hline Percentual em relação aos SPHS anual & $7,86 \%$ & $19,35 \%$ & $11,56 \%$ & $10,28 \%$ & $13,82 \%$ \\
\hline
\end{tabular}

Fonte: Autoria Própria.

Através da comparação das médias de registros de requisições por $100 \mathrm{~m}^{2}$ durante o período disponível para cada edificação (Figura 6), é observado que edificações com a mesma tipologia de uso mas com idades diferentes de ocupação não têm características de solicitação de manutenção dos SPHS similares. Em alguns casos, edificações novas apresentam incidência de registros de manutenção bem superior a edificações mais antigas.

Figura 6 - Comparação das médias de número de requisições $/ 100 \mathrm{~m}^{2}$ entre todas as edificações estudadas

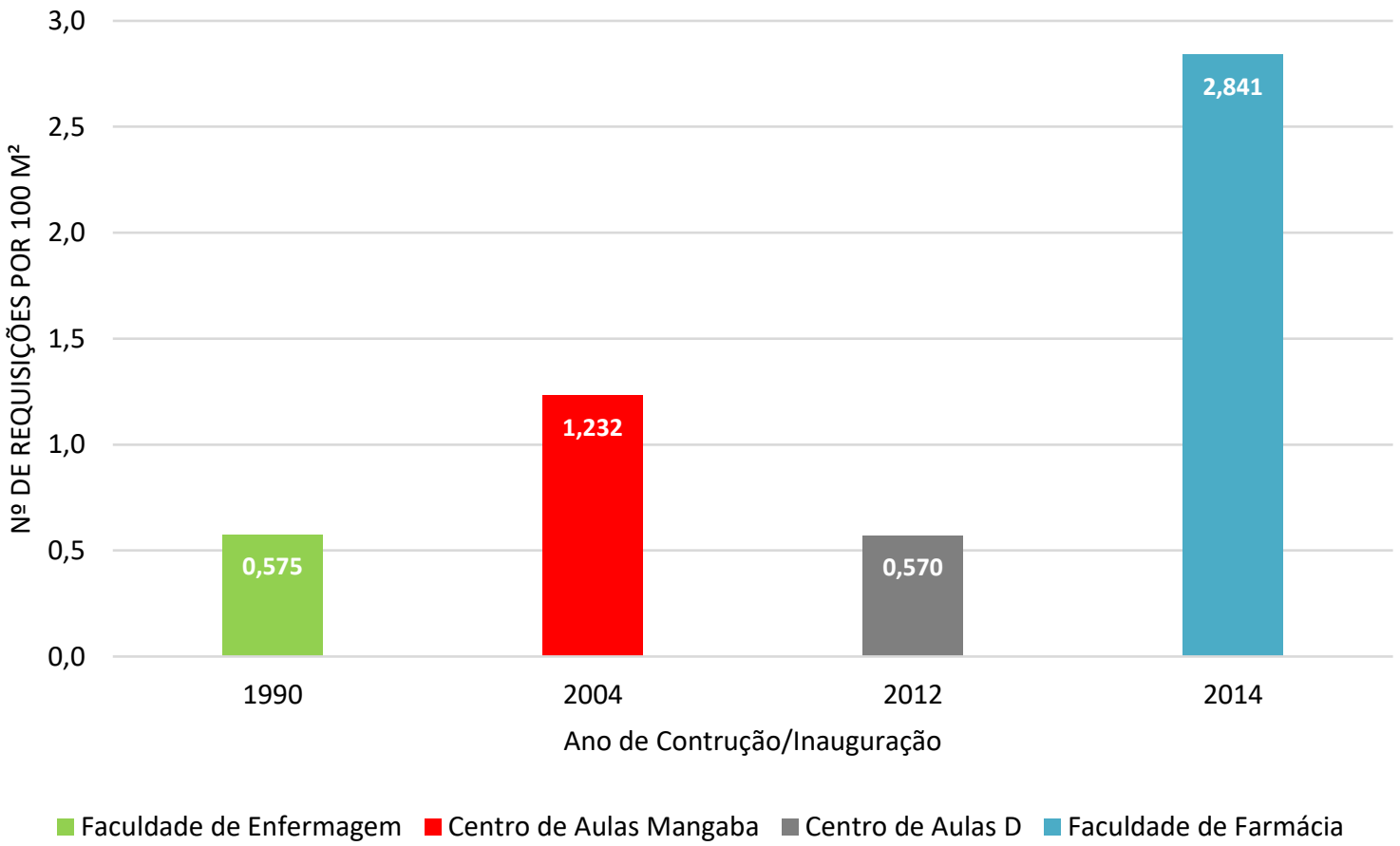

Fonte: Autoria Própria.

\section{CONSIDERAÇÕES FINAIS}

Observou-se durante o período de avaliação uma participação significativa de edifícios com menos de 5 anos nas requisições de manutenção dos SPHS da instituição, com patamares superiores a $30 \%$ na maioria do período. Além disso, é destaque o prédio da Faculdade de Farmácia que recebeu um elevado número de requisições de serviço antes mesmo da 
edificação ter sido inaugurada oficialmente pela instituição, o que indica que nesse período os níveis de uso e ocupação ainda estavam inferiores aos projetados.

Considerando as observações realizadas nos primeiros anos de operação dos sistemas das edificações, observou-se que o comportamento das demandas de manutenção nos SPHS não foi uniforme entre os casos de estudo.

Dentro desse período, defeitos e vazamentos em torneiras, registros e válvulas de descarga estão relacionados ao uso de equipamentos de baixa qualidade ou instalação inadequada desses aparelhos. Relatos de entupimentos de ralos, sifões e bacias sanitárias e descolamento de elementos, especialmente durante o primeiro ano pós obra são relacionados a falhas durante a execução. Erros relacionados a falta de água, pressão deficiente, retorno de odor e alagamento de pavimentos por águas pluviais podem estar relacionados a deficiências nos projetos que não foram corrigidas na fase de execução.

Ressalta-se que em uma obra pública, em última esfera de trabalho, encontra-se a fiscalização da obra, que deve avaliar os projetos recebidos e acompanhar a execução. Face a todas as solicitações recebidas durante os primeiros anos de operação desses edifícios, é evidente a necessidade do aprimoramento desse processo durante a execução de um empreendimento.

\section{REFERÊNCIAS}

ASSOCIAÇÃO BRASILEIRA DE NORMAS TÉCNICAS. NBR 5674:2012. Manutenção de Edificações. Procedimento. Rio de Janeiro: ABNT, 2012. 6p.

NBR 5626/2020. Sistemas prediais de água fria e água quente - Projeto, execução, operação e manutenção. Rio de Janeiro: ABNT, 1994. 56p.

BOSCHETTI, L. A. Análise das falhas pós-obra nos sistemas prediais de edifícios residenciais multipavimentos. 2010. 160 f. Dissertação (Mestrado em Habitação) - Instituto de Pesquisas Tecnológicas do Estado de São Paulo, São Paulo, 2010.

CRUZ, D. C. Análise de solicitações de assistência técnica em empreendimentos residenciais como ferramenta de gestão. 2013. 167 p. Dissertação (Mestrado em Estruturas e Construção Civil) Universidade Federal de Goiás, Goiânia, GO.

MORAIS, G. A. T.; LORDSLEEM, A. C. J. A Building maintenance management activities in a public institution. Engineering, Construction and Architectural Management, v. 26, ed.1, 2019. p85-103.

PRADO, G. B. Aplicação do método G.U.T. para priorização de intervenções em manifestações patológicas de sistemas prediais em edifícios universitários. 2017. 92 p. Dissertação (Mestrado em Estruturas e Construção Civil) - Universidade Federal de São Carlos, São Carlos, SP.

SANTOS, F. P.; LAGE, E. G. S.. Patologias dos sistemas hidráulicos e sanitários da Escola Dom Domingos Carrerot. Engineering Sciences, v.8, n.1, p.17-26, 2020.

TEIXEIRA, P. C.; REIS, R. P. A; GNIPPER, S. F.; MONTEIRO, J. V. Estudo de patologias nos sistemas prediais hidráulicos e sanitários do prédio do ciclo básico II da UNICAMP. Revista eletrônico de Engenharia Civil, v. 1, ed.2, 2011. p34-50. 